\title{
Autonomia, trajetórias e saberes de trabalhadores estudantes da Educação de Jovens e Adultos
}

\section{Autonomy, trajectories and knowledge of workers and students of Adults and Adolescents Education}

\author{
Ivan Livindo de Senna Corrêa* \\ Universidade Federal do Rio Grande do Sul \\ Maria Clara Bueno Fischer** \\ Universidade Federal do Rio Grande do Sul \\ Juliana Silva dos Santos*** \\ Universidade Federal do Rio Grande do Sul
}

Resumo O estudo objetiva analisar a construção da autonomia, as trajetórias de vida e trabalho e também os saberes dos trabalhadores autônomos e estudantes da Educação de Jovens e Adultos (EJA) do Colégio de Aplicação da UFRGS. O estudo também procura encontrar pistas do que leva esses sujeitos a retornarem à escola. A coleta de dados foi realizada através de um questionário e uma entrevista semiestruturada. Os resultados obtidos foram: a) os motivos do retorno à escola são conhecimento, crescimento pessoal e ascensão no emprego; b) a autonomia é relativa às condições de trabalho e a tomada de decisões; c) as trajetórias são fragmentadas, as quais perpassam o trabalho infantil e a exclusão escolar; d)os saberes da experiência constituem-se pela observação e relações cotidianas e pela busca autônoma de informações e conhecimentos.

PALAVRAS-CHAVE: Autonomia, Saberes, Educação de jovens e adultos.

\begin{abstract}
This study aims to analyze the construction of autonomy, life trajectories and the work, as well as the knowledge of self-employed workers and students of Adult and Adolescents Education (EJA) of Colégio de Aplicação from UFRGS. The study also tries to find reasons that made these individuals return to school. The data collecting was done through questions and a semi structured interview. The obtained results were: a) the reasons for returning to school were knowledge, personal improvement and job upward; b) the autonomy is relative to work conditions and decision making; c) the trajectories were fragmented throughout child labor and school exclusion; d) the knowledge experience is constituted by the observation, daily relationships and by the autonomously search for information and knowledge.
\end{abstract}

KEYWORDS: Autonomy, Knowledge, Adult and adolescents education. 


\section{Introdução}

Os estudos sobre autonomia, trajetórias e saberes são temáticas pertinentes à educação, principalmente quando as políticas públicas apontam para a expansão de uma educação politécnica visando à aproximação dos saberes escolares aos saberes do trabalho (SAVIANI, 2007; MOURA, LIMA FILHO; SILVA, 2012). A Educação de Jovens e Adultos (EJA), no Brasil, vem, em sua historicidade pedagógica, construindo propostas que buscam aproximar saberes do trabalho com a educação escolar. Sendo boa parte dos estudantes da EJA dotada de experiências e saberes provenientes das relações cotidianas e de trabalho pode, assim, dialogar com os saberes eruditos ou científicos presentes na educação escolar. Porém, faz-se necessário investigar se os motivos que levam esses estudantes a retornarem à escola compreendem a dialogicidade dos saberes da experiência e dos saberes eruditos.

O conhecimento dos motivos do retorno à escola possibilitará pensar a EJA como um espaço "de instruir pessoas já dotadas de uma consciência formado$\mathrm{ra}$ - ainda que quase ingênua - com hábitos de vida e situação de trabalho que não podem ser arbitrariamente modificados" (PINTO, 2010, p. 89). Todavia, esse instruir não significa uma transmissão de saberes, mas um processo de problematização, de diálogo e de instrumentalização dos sujeitos para a inclusão e a transformação social.

Assim, com a intenção de contribuir às reflexões sobre a EJA, objetivou-se, com essa pesquisa: identificar e analisar a construção da autonomia, as trajetórias e os saberes dos estudantes e trabalhadores autônomos da EJA, do Colégio de Aplicação da UFRGS. Além de encontrar pistas do que leva os Jovens e Adultos a retornarem à Escola.

Como instrumentos de coletas de dados, utilizou-se um questionário com questões abertas e fechadas e uma entrevista semiestruturada com quatro estudantes, trabalhadores autônomos, que concordaram em participar da pesquisa. Aplicou-se no $1^{\text {o }}$ semestre de 2011 o questionário aos 67 estudantes da EJA do Colégio de Aplicação da UFRGS e, no $2^{\circ}$ semestre de 2011, realizou-seaentrevista semiestruturada. O questionário permitiu recolher as seguintes informações: sexo, idade, anos de escolaridade antes da EJA, profissões, série em que deixaram de estudar, motivos do retorno aos bancos escolares e suas expectativas com a EJA.

A entrevista possibilitou conhecer as trajetórias de vida, trabalho e estudo de quatro estudantes que concordaram em falar sobre suas experiências ${ }^{1}$ : Marisa de Oliveira (48 anos) que possui uma lanchonete, os cabeleireiros Renato Pereira (49 anos) e Vitor Câmara (37 anos) e o Agente de Coleta ${ }^{2}$ João Fagundes (39 anos).

Segundo Dubar (1998, p. 10), o estudo das trajetórias, como estratégia metodológica, possibilita conhecer as trajetórias objetivas e subjetivas, as trajetórias objetivas compreendem "a sequência de posições sociais ocupadas por um indivíduo ou sua linhagem". As trajetórias subjetivas são fruto de um "enredo posto em palavras pela entrevista biográfica e formalizado pelo esquema lógico, reconstruído pelo pesquisador por meio da análise semântica" (DUBAR, 1998, p. 13) e permite um maior entendimento da construção da autonomia e dos saberes dos sujeitos da pesquisa. 
Com o estudo das trajetórias, foi possível refletir sobre: a volta à escola e a esperança de ampliação de saberes; a construção da autonomia do trabalhador; o trabalho infantil; a escolha da profissão; e os saberes oriundos da experiência.

\section{A volta à escola e a esperança de ampliação de saberes}

No primeiro semestre de 2011, estavam matriculados, na EJA do Colégio de Aplicação da UFRGS, 115 alunos, 28 no Ensino Fundamental (EF) e 87 no Ensino Médio (EM). Em Junho, 17 alunos tinham evadido, 20 alunos estavam com excesso de faltas e 67 frequentavam as aulas assiduamente e responderam o questionário.

Dos 67 sujeitos da pesquisa, 13 frequentavam o $4^{\circ}$ módulo do EF e 54 os três módulos do EM, dos quais 37 são homens e 30, mulheres. A faixa etária variou entre 14 e 69 anos, estando a maioria entre 30 a 49 anos de idade. No que se refere ao trabalho, no período em que a pesquisa foi realizada, 49 estavam trabalhando e 18 desempregados. Dos que estavam trabalhando, 31 tinham carteira assinada e seis, não; oito trabalhavam por conta própria ${ }^{3}$ e quatro são funcionários públicos. Entre os desempregados, 11 eram menores de 20 anos. As ocupações profissionais são diversas, predominando empregados no comércio e vendas (28\%), serviço de vigilância (12\%), trabalho autônomo (12\%), empregados domésticos (6\%), desempregados (27\%) e outras ocupações (15\%).

Deixaram a escola regular: 17 antes da $4^{\mathrm{a}}$ série; 17 entre $5^{\mathrm{a}}$ e $6^{\mathrm{a}} ; 25$ entre a $7^{\mathrm{a}}$ e $8^{\mathrm{a}}$ série do EF e oito no $1^{\mathrm{o}}$ ano E.M. Predominando, na $5^{\mathrm{a}}$ série, as estudantes mulheres e, na 7 a os estudantes homens. Nas tabelas que seguem, apresentam-se os motivos que levam os estudantes a retornarem à escola e suas percepções quanto à educação escolar.

Tabela 1 - Motivos que levaram os sujeitos a matricular-se na EJA.

\begin{tabular}{lcc}
\hline & Frequência & $\mathbf{\%}$ \\
\hline $\begin{array}{l}\text { Mais conhecimento, crescimento pessoal e preparação } \\
\text { para a vida }\end{array}$ & 30 & 44,8 \\
\hline Ascensão social ou conseguir um emprego melhor & 23 & 34,3 \\
\hline Não respondeu & 5 & 7,5 \\
\hline Socialização e ascensão no trabalho & 4 & 6,0 \\
\hline Continuação dos estudos - técnico ou superior & 3 & 4,5 \\
\hline Conhecimento e diploma & 1 & 1,5 \\
\hline Melhor se expressar & 1 & 1,5 \\
\hline Total & 67 & 100,0 \\
\hline
\end{tabular}

Nesta tabela, pode-se verificar que, entre os motivos do retorno à escola, predomina a necessidade de ter mais conhecimento que a sociedade, o trabalho e as próprias relações afetivas impõem, como também, num segundo momento, impera a ligação entre o estudo e a possibilidade de ascensão social e a obtenção de um melhor emprego. 
Observa-se que a necessidade de conhecer ou saber é intrínseca ao ser humano e suas relações com o mundo e os outros homens (FREIRE, 1987; CHARLOT, 2000; PINTO, 2010). Para Charlot (2000 p. 78), "a relação com o saber é relação de um sujeito com o mundo, com ele mesmo e com os outros. É relação com o mundo como conjunto de significados, mas também, como espaço de atividades, e se inscreve no tempo". Assim, ao retornarem à escola, os estudantes buscam a transformação de sua realidade e veem o conhecimento erudito ou escolar como um passaporte social.

Nesse aspecto, a EJA é buscada pelos sujeitos da pesquisa como espaço de tensão e ampliação de "conhecimentos que lhes permitam elevar-se em sua condição de trabalhador" (PINTO, 2010, p. 35), o que se expressa na fala de Renan, estudante do terceiro módulo do EM: "a educação é fundamental na nossa vida, para ter mais conhecimento, ser mais inteligente, sábio, saber se portar melhor na sociedade, entre tantos outros benefícios". Nessa fala, o conhecimento aparece como uma possibilidade de inclusão social, de ser aceito socialmente ao "saber se portar melhor na sociedade". Aqui, o saber escolar aparece como um aspecto distintivo no sentido de que, ao possuir um saber escolar, ele estará incluído no espaço social que distingue as pessoas pelo nível escolar que possuem e com maior autonomia para a escolha de um emprego.

Sendo o segundo motivo a obtenção de um emprego melhor, como relata Karina, estudante do primeiro módulo do EM: "a educação escolar é importante para o desenvolvimento do raciocínio, atualização escolar e poder ir a frente na carreira profissional, prestar concurso público". Conforme Lahire (1997, p. 256), devido "as exigências cada vez mais elevadas em matéria de cursos de qualificação, o diploma se torna uma necessidade (mesmo que insuficiente) de entrada no mercado de trabalho para o conjunto dos grupos sociais". Para tanto, estudar e adquirir um diploma faz com que alguns alunos vejam a escola como um caminho para a ascensão, na busca de um emprego estável e de uma vida social mais justa. Nessa perspectiva, o diploma representa um passaporte para disputar uma vaga de emprego tanto na iniciativa privada como nos serviços públicos (CHARLOT, 1996; BOURDIEU, 2011; LAHIRE, 1997).

Dessa forma, há uma idealização da escola por parte dos estudantes e da sociedade, que pensam que: ao adentrarem os muros da escola, suas vidas serão resolvidas, suas possibilidades de emprego elevar-se-ão e, certamente, suas vidas melhorarão.

Tabela 2 - O que os estudantes gostam na escola?

\begin{tabular}{lcc}
\hline & Frequência & \% \\
\hline Colegas e dedicação dos professores & 29 & 43,3 \\
\hline As aulas e os conhecimentos das disciplinas & 24 & 35,8 \\
\hline Tudo & 7 & 10,4 \\
\hline Convivência e conhecimentos & 4 & 6,0 \\
\hline Disciplinas optativas (oficinas) & 2 & 3,0 \\
\hline Trabalhar em grupo & 1 & 1,5 \\
\hline Total & 67 & 100,0 \\
\hline
\end{tabular}


O aspecto que os estudantes mais gostam na escola é as relações com os colegas e professores, muitos expressam o respeito que têm pelos professores e a importância do espaço escolar na formação de relações de amizade. Como escreve Roselei, estudante do primeiro módulo do EM: "gosto dos professores porque eles procuram ensinar o máximo que eles podem para nós da EJA. Gosto também dos colegas". Para Charlot (1996, p. 54), existe uma relação direta de "gostar do professor, gostar da matéria", dos "colegas e o ambiente escolar" e aprender as coisas e ter sucesso na escola.

Um segundo ponto é gostar das aulas e das "matérias" ensinadas nas diversas áreas de conhecimento, na escola. Joseane e Ernesto, estudantes do segundo módulo do EM, relatam: "gosto mais das aulas que são dadas de maneira mais descontraída, com slide, aulas de Educação Física e as tarefas em grupos" (Joseane); "eu gosto de aprender matérias novas porque vai ajudar no meu aprendizado" (Ernesto). Observa-se, nas respostas desses estudantes, que, quando eles vão à escola, querem que as aulas proporcionem momentos de aprendizagem e é por esse motivo que os alunos mobilizam-se. Charlot (1996, p. 55) afirma que a "mobilização em relação à escola é investimento no próprio fato de ir à escola e aprender coisas".

Um fato que chamou a atenção e motivou a investigar os trabalhadores autônomos e estudantes foi que eles afirmaram não estar retornando à escola por exigências de patrões ou para obtenção de um emprego melhor, mas para adquirir "mais conhecimento e crescimento pessoal". Para Pinto (2010, p. 47), sendo o conteúdo da educação popular por excelência e direito de todos, "o conteúdo da educação não é um adorno de espírito, mas um 'instrumento de realização do homem' dentro de seu ambiente social”, isto, talvez, justifique o mero desejo de retornar à escola, para ser mais, aprender mais e ampliar sua autonomia.

\section{A construção da autonomia do trabalhador}

A escolha e a permanência como trabalhador autônomo é, para muitos, uma forma de garantir sua autonomia, principalmente em relação ao tempo. Para Renato e Vitor (estudantes do $1^{\circ}$ módulo do Ensino Médio), com a flexibilidade do horário no trabalho, eles podem "curtir os filhos", já, para João (estudante do $1^{\circ}$ módulo do Ensino Médio), este tempo significa cuidar de sua mãe e frequentar a EJA, e Marisa (estudante do $3^{\circ}$ módulo do Ensino Médio) decidiu não abrir a lanchonete durante a madrugada para estudar.

Contudo, o trabalho autônomo ou por conta própria não garante, em si, a autonomia, mas vem sendo uma das alternativas dos trabalhadores para enfrentar a crise do emprego ocasionada pelas constantes mudanças no mundo do trabalho (ANTUNES, 2010; TIRIBA, 1998). Fato que se observa no aumento constante do número de trabalhadores nesta condição nas regiões metropolitanas, que, segundo IBGE (2012), passou dos 3,533 milhões em janeiro de 2003 para 4,082 milhões em Janeiro de 2012. Como se vê, o trabalho por conta própria permanece sendo alternativa aos desempregados. Segundo Antunes (2010, p. 17), a re-estruturação produtiva, uma das razões do desemprego, é fruto do receituário da acumulação flexível, intensificada no Brasil, a partir dos anos 1990, que tem tido, como consequência, o aumento dos postos de trabalho através da "sub-contratação e de terceirização da força de trabalho". Contraditoriamente, ao mesmo tempo em que a terceirização apresenta-se como uma precarização do trabalho, ela possibilita o controle pelos trabalhadores do processo 
produtivo no interior das unidades produtivas autônomas, ou seja, permite o aumento da autonomia do trabalhador.

Para Cattani (2000, p. 146), a autonomia é um termo originário do grego e "significa a condição de um indivíduo ou de um grupo suscetível de se determinar por si mesmo, segundo suas próprias leis". Este conceito pode ser abordado em três níveis: individual, atividades laborais e ação política. Neste estudo, analisa-se a autonomia nas atividades laborais que, de acordo com Cattani (2000, p. 147), "implica a possibilidade de escolha das tarefas, dos meios e do sentido do trabalho, resultando em dignidade e satisfação". Se o trabalho por conta própria garante, de certo modo, um nível significativo de autonomia, em que sentido frequentar a EJA contribui ou limita a manutenção ou ampliação desta?

Segundo Razeto (2005), com a crise do emprego, os trabalhadores têm se inserido na "economia popular" cia e de vida. Ao analisar as trajetórias dos entrevistados, observa-se que Renato, Vitor e João construíram, no trabalho autônomo, uma estratégia de vida, demonstrando satisfação no trabalho por conta própria. Desse modo, o processo de autonomia conquistado na vida profissional instiga, nos sujeitos entrevistados, a procura pelo conhecimento, com intuito de aprender mais sobre seu trabalho ou para atender melhor seu público.

No que se refere à atividade autônoma, Renato diz: "hoje eu gosto de alisar cabelo e fazer penteado (...) corto cabelo só de clientes antigas"; Vitor afirma que "tudo que faço na vida é com amor, senão eu não faço (...) quando não sei e não quero cortar um cabelo, eu passo para outro colega"; e João: "o que eu mais gosto é de ir para o mato, ficar com os bichos e de ficar acompanhando o comportamento, fazendo fotos"; Marisa gosta de conversar, dar conselhos, "quando terminar os meus estudos eu quero ser assistente social". Esses relatos podem exemplificar o que Razeto (2005, p. 38) chama de estratégias de vida, que é "quando as pessoas valorizam certos espaços da atividade que realizam (a liberdade, o companheirismo, a autogestão), ou as consideram melhores alternativas possíveis [...]e, em consequência, 'apostam' na iniciativa empreendida como opção permanente”. Nesse aspecto, a EJA contribui para a autonomia no sentido de ampliar as possibilidades de escolhas e de realização das expectativas de vida.

Pode-se dizer que a construção da autonomia dos sujeitos da pesquisa não ocorre isoladamente, foi se conquistando num processo relacional: na aprendizagem da profissão e no diálogo com colegas, amigos, clientes e familiares. Como afirma Machado (2010, p. 53),"autonomia é um processo de decisão e de humanização que vamos construindo historicamente, a partir de várias, inúmeras decisões que vamos tomando ao longo de nossa existência”. Só é possível percebê-la se forem observadas trajetórias ou os percursos dessa construção.

\section{A trajetória dos sujeitos da pesquisa}

Franzoi (2003) classifica, em seus estudos sobre trajetórias, três tipos: trajetória contínua, trajetória fragmentada e trajetória negada. Para Franzoi (2003, p. 108), trajetória contínua refere-se aos percursos "realizados em uma mesma área ao longo da sua vida profissional, ou isso passa a acontecer a partir de um determinado momento 
em um período suficiente para nortear suas iniciativas formativas". A trajetória fragmentada "designa as trajetórias que, quanto à ocupação, podem ser consideradas 'erráticas', sem continuidade nem em um mesmo local de trabalho, nem sequer em uma mesma área de atividade" (p. 101-102). Já, a trajetória negada é "situação encontrada dentre aqueles que possuem trajetórias fragmentadas: a que diz respeito aos que não têm nenhuma referência profissional em sua trajetória, fazendo com que seus projetos sejam ainda mais difusos" (p. 118-119). Entre os sujeitos da presente pesquisa, conforme análise, identificaram-se casos de trajetórias contínuas e fragmentadas.

As características similares dos quatros sujeitos são: vivenciaram o trabalho infantil, pararam de estudar na adolescência ${ }^{5}$ para trabalhar; foram empregados assalariados com vínculo formal de trabalho antes de optarem por trabalhar por conta própria; procuraram a EJA, não por exigência para o mercado de trabalho, mas por interesse pessoal de concluir o Ensino Médio e, posteriormente, ingressar no Ensino Superior.

\section{O trabalho infantil}

Segundo a pesquisa mensal de emprego das regiões metropolitanas brasileiras (IBGE, 2012), em janeiro de 2012, 45.000 pessoas de 10 a 14 anos trabalhavam nas regiões metropolitanas de: Recife, Salvador, Belo Horizonte, Rio de Janeiro, São Paulo e Porto Alegre. Os dados mostram que o trabalho de crianças e adolescentes é ainda presente no Brasil, como é percebido na trajetória dos sujeitos da pesquisa. Marisa começou a trabalhar como doméstica aos 13 anos; Renato, na agricultura familiar, desde os sete anos; Vitor com 10 anos prestava serviços a uma padaria e João começou a trabalhar com 10 anos num supermercado. Marx (1988), ao denunciar que não existia limite legal de idade no trabalho industrial, na Inglaterra do século XIX, traz relatos de crianças de sete a nove anos que trabalhavam cerca de 15 horas por dia. Esse é um fenômeno presente em toda a história do capitalismo e é realidade no Brasil e em outros países ${ }^{6}$. No que se refere ao Brasil, conforme os dados do IBGE (1997), $4,3 \%$ das crianças de 10 a 12 anos que trabalhavam estavam na indústria de transformação. Em estudos realizados por Navarro (2010), na indústria de calçados de couro na cidade de Franca-SP, o processo de terceirização, proporcionado pela reestruturação produtiva no setor calçadista, transforma o domićlío em unidade produtiva, onde mulheres e crianças realizam o trabalho de costura manual. Além da indústria, segundo IBGE (1997), os setores urbanos que empregam o trabalho infantil são o comércio de mercadorias $(11,9 \%)$ e a prestação de serviços $(10,9)$, realidade que remete aos sujeitos da pesquisa.

$\mathrm{Na}$ adolescência, todos foram forçados a deixar a escola para trabalhar: Vitor (caixa de supermercado); João (organizador de depósito); Renato (servente de pedreiro); Marisa (doméstica).

\section{A escolha da profissão}

As histórias de desemprego presentes nas trajetórias dos entrevistados coincidem com o período de reestruturação produtiva que passou o Brasil nos anos 1990 e, consequentemente, vivenciou-se, segundo Antunes e Alves (2004, p. 348) "as condições mais desprovidas de direitos e em condições de instabilidade cotidiana, dada pelo 
trabalho part-time, temporário, e precarizado". O trabalho precarizado, temporário, levou esses trabalhadores-estudantes da EJA a construírem seus próprios espaços de trabalho no setor de serviços. Isso não significa grandes conquistas financeiras, pois, como esses sujeitos, muitos outros trabalhadores desempregados, buscam o setor de serviços como alternativa de sobrevivência; o que pressiona para baixo o ganho mensal, devido à perda de clientes.

Como diz Vitor: "Eu sou um bom profissional... mas o problema hoje é: tu és um bom cabeleireiro, frequentou uma escola boa, e tem outros que aprenderam no oba, oba, e cobram menos". Essa é a mesma reclamação de Marisa: "colocamos a lancheria há quase 20 anos...éramos dois, hoje somos entre cinco”. Renato ressalta que outros cabeleireiros usam produtos proibidos, oferecendo, assim, melhores preços. Já João trabalha de forma precarizada como Agente de Coleta em pesquisas ambientais para PUC-RS e UFRGS, e seu trabalho depende dos financiamentos dos projetos de pesquisa na área das Ciências Biológicas. Observa-se que mesmo em situação precária, os trabalhadores constroem saberes necessários ao exercício de seus ofícios e seus segredos e/ou experiências garantem-lhes o acesso ao trabalho e a sua sobrevivência.

Após a análise das trajetórias dos quatros sujeitos, pode-se dizer que apenas Renato apresentou uma trajetória contínua, porque se mantêm desde a juventude vinculado à mesma ocupação, frequentou vários cursos de capacitação e, após um curso no exterior, diz: "todo mundo me convida para dar cursos". Marisa, apesar de estar há anos na mesma profissão, ingressou no curso de assistente social, conforme informou por telefone em fevereiro de 2012. João, mesmo contente com sua profissão, é instável, depende dos pesquisadores, e tem momentos em que fica sem ocupação. Vitor que teve várias ocupações, há pouco tempo ingressou na profissão de cabeleireiro.

\section{Os saberes oriundos da experiência}

Ao buscar identificar os saberes oriundos da experiência, tentou-se compreender a odisseia dos excluídos que lutam pela sobrevivência no processo de exclusão que se instituiu com a reestruturação produtiva dos anos 1990 no Brasil. Nesse sentido, busca-se conhecer os saberes dos sujeitos da pesquisa. Para isso, compreendese saberes no sentido em que Freire (1987, p. 58) define: "só existe saber na invenção, na reinvenção, na busca inquieta, impaciente, permanente, que os homens fazem no mundo, com o mundo e com os outros. Busca esperançosa também”. Então, nessa busca constante de ser no mundo, os sujeitos da pesquisa, através das relações interpessoais e cotidianas, forjaram os saberes de seu trabalho.

Esses saberes do trabalho, principalmente em seu aspecto do saber fazer (prática) e em outros saberes humanos, segundo Barato (2004, p. 151), são fruto das relações entre informação ${ }^{7}$, conhecimento ${ }^{8}$ e desempenho ${ }^{9}$ e esses componentes "guardam relações de interdependência e, ao mesmo tempo, são relativamente autônomos". Também, para Rose (2007, p. 29), "o saber no trabalho oferece uma análise do trabalho físico e da inteligência, e uma reflexão acerca de como é possível pensá-los de uma maneira mais clara e mais justa". Segundo esses autores, observa-se que os sujeitos constroem saberes do trabalho através do diálogo, pela associação de experiências passadas com o contexto atual, pela busca de informações em bibliografias ou mesmo junto a profissionais mais experientes. Dessa forma, a pesquisa buscou identificar os aspectos relevantes para a construção dos saberes dos sujeitos entrevistados. Outro 
fator importante é o fazer bem que se relaciona à satisfação do cliente e refere-se ao desempenho (BARATO, 2004). Ao perguntar aos entrevistados como aprenderam a profissão, verifica-se que só conseguiram o almejado na busca inquieta, na solidariedade, no estudo e na invenção.

Marisa, ao ser questionada como aprendeu a fazer lanches, responde "aprendendo, eu ia nos "Xis" [Lancherias] e via o que eles colocavam e depois tentava fazer o meu". Marisa desenvolveu o processo de fazer o bife de hambúrguer e a maionese, testando e pedindo o parecer dos clientes, parentes e amigos. Ela diz: "eu fiz um teste com os bifes e meu cunhado disse para colocar um pouquinho de óleo e deu certo". A maionese é preparada diariamente para não estragar e Marisa relata a preocupação "o que eu não gostaria para mim eu não faço para o cliente".

Renato, durante o em tempo que trabalhava como recepcionista em uma estética, nos anos 1980, cortava o seu próprio cabelo escondido. Técnica que havia aprendido com o seu pai agricultor. Segundo ele, seu pai mandava os filhos fazer uma fila e "passava a máquina no cabelo de todos". Ele, como não gostava disso, começou, ainda criança, a cortar o próprio cabelo a mão.

Renato comenta como começou sua vida profissional: "um dia, eu estava sozinho e fui cortar o meu cabelo porque não gostava do corte do cabeleireiro, que era o dono do salão e não sabia cortar cabelo afro ${ }^{10}$ então, eu mesmo preferia cortar o meu". Renato relata que um cliente, ao chegar antecipado para o seu horário, viu-o cortando o próprio cabelo, e pediu para voltar, no dia seguinte, no seu intervalo, para que Renato cortasse seu cabelo do mesmo jeito que havia cortado o seu próprio. Assim, dialogando com os clientes e recuperando saberes construídos em sua família, iniciouse sua trajetória profissional.

João também aprendeu sua profissão pela observação, fez amizade com um biólogo, estudante de Mestrado em Biologia na UFRGS que trabalhava pesquisando bugios no Rio Grande do Sul. Como ele conhecia os matos da região sul da cidade de Porto Alegre, foi convidado a trabalhar como guia. Então, começou a envolver-se nas atividades de pesquisa, observando os estudantes de Biologia, participando dos Cursos de Extensão da UFRGS: "aprendi a fazer a descrição dos animais com os alunos de Biologia, que, agora, são todos Doutores". Hoje, segundo ele, é bem reconhecido "na área de primatologia e comportamento do bugio" e sempre presta serviços para pesquisadores.

Já Vitor, que tem poucos anos como cabeleireiro, aprendeu a profissão realizando cursos em salões de beleza que, além de atender ao público, propõem-se a formar novos cabeleireiros. Aprendeu os truques da profissão, observando e perguntando aos colegas. Segundo Vitor, "tem uns truques na profissão, o cabeleireiro tem que conhecer a pessoa, já no conversar (...)". "A pessoa chega e diz: eu quero fazer 'um relaxamento no cabelo'(...) tu não pode dar um chute ou usar um produto barato, eu sempre procuro fazer o certo". Os depoimentos de Vitor e de Renato coincidem com os estudos sobre cabeleireiros realizados por Rose (2007, p. 93). Segundo o autor,"o que entusiasma é a arte da coisa toda, o uso da sua técnica de modo a corresponder às necessidades do cabelo, interagir com ele, observando o aparecimento do corte". 
Observa-se que os sujeitos da pesquisa, em todo o processo, buscam informações sobre as técnicas de sua profissão em dois campos: na literatura e no diálogo com colegas e clientes. Os conhecimentos sistematizados são adquiridos em cursos e em literaturas específicas e o desempenho dá-se na prática e envolve as informações e os saberes ou conhecimentos adquiridos na aprendizagem e na atividade profissional. Pode-se dizer que o saber fazer dos sujeitos da pesquisa é mais que a aplicação de uma técnica, é uma reinvenção constante e complexa que envolve conhecimentos, diálogos, habilidades e o contexto em que se encontra.

\section{Conclusão}

Fruto do diálogo entre o referencial teórico e os dados empíricos, esta pesquisa possibilitou identificar, primeiramente, os motivos do retorno à escola na EJA, como também, nos quatro sujeitos entrevistados, identificaram-se os espaços de autonomia, as trajetórias de vida e trabalho e os saberes dos sujeitos estudados.

O motivo mais significante para o retorno à escola foi a necessidade de conhecimento escolar, pois, a sociedade, na forma que está organizada, exige crescimento pessoal e cognitivo para a obtenção de um melhor emprego ou até mesmo para ingressar num curso superior. A EJA, para os estudantes, é um espaço de retorno em busca do tempo perdido, da adolescência interrompida e de conhecimentos que possibilitem uma maior inserção social. (PINTO, 2010; FREIRE, 2000).

A autonomia foi expressa pela possibilidade de conquista de um espaço próprio de trabalho, no qual se possa decidir o que fazer, como fazer e para quem fazer, em diálogo com os clientes e colegas de profissão. Os relatos dos sujeitos da pesquisa vão ao encontro do conceito de autonomia de Cattani (2000), ao expressarem satisfação por poderem ser livres nas suas escolhas e na concepção das atividades de trabalho.

As trajetórias dos quatros sujeitos entrevistados, assemelham-se na luta pela sobrevivência através do trabalho infantil, na falta de condições de conciliar o trabalho e a escola regular e de terem trabalhado em diversas áreas até encontraremse no trabalho por conta própria. Nesse caso, predominou a trajetória fragmentada (FRANZOI, 2003), apresentada por três pessoas e uma trajetória contínua que, apesar de, na adolescência, mudar diversas vezes de ocupação, construiu ao longo de sua vida uma carreira profissional.

Em relação à construção dos saberes no fazer profissional, inicialmente, o processo desenvolveu-se na observação dos mais experientes, na busca por informações e conhecimentos em cursos e em bibliografia específica, juntamente com suas percepções e intervenções como sujeito trabalhador. Esses dados coincidem com os estudos de Barato (2004) e Freire (1987) quanto à importância das relações e experiências na construção dos saberes.

As reflexões, trazidas neste artigo, apontam a EJA como a alternativa para homens e mulheres concluírem a Educação Básica. Para os sujeitos do estudo, a escola é um espaço de apropriação de conhecimentos, de encontro e de ampliação dos saberes da experiência em diálogos com os saberes escolares. Os relatos dos processos de construção de saberes da experiência mostram que as pessoas não constroem conhecimentos numa relação professor/aluno, os conhecimentos são construídos por reflexões 
sobre o fazer, no diálogo com pares e mestres, observando, problematizando e criando estratégias de resolver problemas. Essas constatações reforçam a necessidade de construir, na EJA, uma "pedagogia da autonomia" (FREIRE, 1997), em que seja possível vivenciar a pesquisa, o respeito aos saberes dos educandos, a criticidade, o diálogo, a curiosidade, entre outras características. Além disso, um dos fatores determinantes para a permanência dos jovens e adultos, na escola, é a dedicação dos professores na busca de estratégias que possibilitem aos educandos a construção de autonomia e saberes.

\section{Referências}

ANTUNES, R. Anotações sobre o capitalismo recente e a reestruturação produtiva no Brasil. In. ANTUNES, R.; SILVA, A. M. (Orgs.). O avesso do trabalho. 2 ed. São Paulo: Expressão Popular, 2010. p. 13-24.

ANTUNES, R.; ALVES, G. As mutações no mundo do trabalho na era da mundialização do capital. In. Revista Educação Sociedade. Campinas, v. 25, n. 87, p. 335-351, maio/ago. 2004.

BARATO, J. N. Educação Profissional: saberes do ócio ou saberes do trabalho? São Paulo: Editora Senac São Paulo, 2004. 278 p.

BRASIL. Classificação Brasileira de Ocupações (CBO). Brasília- DF: Ministério do Trabatho e Emprego. Portaria Ministerial n. 397, de 9 de outubro de 2002. Disponível em: <http:// www.mtecbo.gov.br/cbosite/pages/pesquisas/FiltroTabelaAtividade.jsf $>$. Acesso em: $24 \mathrm{de}$ fev. 2012.

BRASIL. Lei n. 8.069, de 13 de julho de 1990 (Estatuto da Criança e do Adolescente). Portal do Ministério da Justiça. Disponível em: <http://portal.mj.gov.br/sedh/spdca/eca.pdf $>$. Acesso em: 24 fev. 2012

BOURDIEU, P. A distinção: crítica social do julgamento. Trad. De Daniela Kern; Guilherme. F. Teixeira. Porto Alegre: Zouk, 2011.

CATTANI, A. D. Trabalho e autonomia. 2 ed. Petrópolis: Vozes, 2000.

CHARLOT, B. Da relação com o saber: elementos para uma teoria. Porto Alegre: Artes Médicas, 2000.

CHARLOT, B. Relação com o saber e com a escola entre estudantes de periferia. Cadernos de Pesquisa. São Paulo. n. 97, maio, 1996, p. 47-63

DUBAR, C. Trajetórias sociais e formas identitárias: alguns esclarecimentos conceituais e metodológicos. Educação \& Sociedade. v.19 n. 62 Campinas Apr.1998. Disponível em: <http://www. scielo.br/scielo.php?script=sci_arttext\&pid=S0101-73301998000300004\&lng=pt\&nrm=iso $>$. Acesso em: 14 nov. 2010.

FRANZOI, N. L. Da profissão como profissão de fé ao "mercado em constante mutação": trajetórias e profissionalização dos alunos do plano estadual de qualificação do Rio Grande do Sul (peq-rs). 2003. Tese (Doutorado em Educação) - Faculdade de Educação. Campinas: Universidade Estadual de Campinas, $2003.250 \mathrm{p}$.

FREIRE, P. A educação na cidade. São Paulo: Cortez, 2000.144 p.

FREIRE, P. Pedagogia da autonomia: saberes necessários a prática educativa. São Paulo: Paz e Terra, 1997.169 p.

FREIRE, P. Pedagogia do oprimido. 17 ed. Rio e Janeiro: Paz e Terra, 1987. 184 p. 
IBGE. Indicadores IBGE: Pesquisa Mensal de Emprego, Agosto 2012. Disponível em: <ftp://ftp.ibge.gov.br/Trabalho_e_Rendimento/Pesquisa_Mensal_de_Emprego/fasciculo_indicadores_ibge/>.Acesso em: 21 set. 2012.

IBGE. Indicadores sociais criança e adolescente IBGE (1997). Disponível em: <http://www. ibge.gov.br/home/estatistica/populacao/criancas_adolescentes/default.shtm>. Acesso em: 31 jan. 2012.

LAHIRE, B. Sucesso escolar nos meios populares: as razões do improvável. São Paulo: 1997.

MACHADO, R. C. F. Autonomia. In. STRECK, D. R.; REDIN, E.; ZITKOSKI, J. J. Dicionário Paulo Freire. 2 ed. Belo Horizonte: Autêntica, 2010, p. 53-54.

MARX, K. O capital: crítica da economia política. Volume I (Os economistas). São Paulo: Nova Cultural, cap. 1-3, p. 45-120, 1988.

MOURA, D. H.; LIMA FILHO, D. Leite; SILVA, M. R. Politecnia e formação integrada: confrontos conceituais, projetos políticos e contradições históricas da educação brasileira. (Trabalho encomendado pelo GT 09 - Trabalho e Educação da ANPEd) In. Anais da 35a Reunião Anual da ANPED - Associação Nacional de Pós-Graduação e Pesquisa em Educação. Porto de Galinhas-PE, 24 de outubro de 2012, 41p.

NAVARRO, V. L. A reestruturação produtiva na indústria de calçados de couro em Fanca (SP). In. ANTUNES, R.; SILVA, A. M. (Orgs.). O avesso do trabalho. 2 ed. São Paulo: Expressão Popular, 2010, p. 67-126.

NUNES, M. L. Revisita à ideia de quilombo: uma reflexão étnico-racial a partir do Quilombo do Cinzento. Dissertação (Mestrado em Políticas Sociais e Cidadania), 2008. Superintendência de Pesquisa e Pós-Graduação. Salvador: Universidade Católica do Salvador, 2008, 167p.

PINTO, Á. V. Sete lições sobre educação de adultos. 16 ed. São Paulo: Cortez, 2010.

RAZETO, L. Economia de solidariedade e organização popular. In. GADOTTI, M.; GUITIÉRREZ, F. Educação comunitária e economia popular. 4 ed. São Paulo: Cortez, 2005, p. $34-58$

ROSE, M. O saber no trabalho: valorização da inteligência do trabalhador. Tradução de Renata Lucia Bottini. São Paulo: Editora Senac São Paulo, 2007, 353 p.

SAVIANI, D. Trabalho e educação: fundamentos ontológicos e históricos. Revista Brasileira de Educação. v. 12 n. 34 jan./abr. 2007.

TIRIBA, L. Economia popular e produção de uma nova cultura do trabalho: contratações e desafios frente à crise do trabalho assalariado. FRIGOTTO, G. (Org.). In. Educação e crise do trabalho: perspectivas de final de século. Petrópolis: Vozes, 1998, p. 189-216

UNICEF. Situação mundial da infância 2011: adolescência uma fase de oportunidades. Fundo das Nações Unidas para a Infância (UNICEF), Fevereiro de 2011. Disponível em: <http:// www.unicef.org/brazil/sowc2011/index.html>. Acesso em: 31 jan. 2012.

\section{Notas}

\footnotetext{
${ }^{1}$ Os sujeitos concordaram com o uso de seus nomes na pesquisa

${ }^{2}$ Segundo a CBO, Agente de Coleta, faz parte da família dos Entrevistadores e recenseadores, código no 4241, que exerce a função de entrevistar ou coletar dados amostrais. No caso do João Fagundes, ele coleta dados sobre comportamento animal para pesquisas biológicas.

${ }^{3}$ Durante todo o texto usamos trabalho por conta própria como sinônimo de trabalho autônomo e caracteriza-se por ausência de supervisão e controle, quando geralmente os trabalhadores são proprietários dos instrumentos de trabalho.
} 
${ }^{4}$ Economia popular segundo Razeto, (2005) e Tiriba (1998) representa a heterogeneidade em que as classes populares se organizam com estratégias de: sobrevivência, subsistência e de vida. Como componente da economia popular encontramos as microempresas, pequenas oficinas, organizações econômicas populares, iniciativas individuais não formais, atividades ilegais e com pequenos delitos e organizações não governamentais.

${ }^{5}$ Adolescência aqui se refere ao conceito adotado pela Lei no 8.069/1990 (Estatuto da Criança e Adolescente), a qual considera adolescente a pessoa entre doze e dezoito anos de idade.

${ }^{6}$ Segundo Unicef (2011, p. 123), na América Latina e Caribe 9\% das crianças entre 5 e 14 anos trabalhavam, sendo que no montante dos países em desenvolvimento $16 \%$ das crianças entre 5 e 14 anos trabalhavam e nos países pouco desenvolvidos $23 \%$ das crianças dessa faixa-etária trabalham.

${ }^{7}$ Segundo Barato (2003, p. 152) informação é a "representação externa (linguagens, imagens, modelos, etc.) utilizada como veículo para se construir a representação interna (conhecimento)”.

${ }^{8}$ Conhecimento é a "representação interna utilizada par guiar a execução. Deve estar armazenada na memória" (op. cit.).

${ }^{9}$ Desempenho é a "execução de operações tendo em vista a obtenção de um dado resultado (op. cit.).

${ }^{10}$ A utilização da expressão cabelo afro, refere-se aos cabelos crespos dos negros e remete a identidade cultural africana. Segundo (NUNES, 2008, p. 19) tanto o uso da expressa cabelo afro, como as diversas formas de arrumá-lo "está analogamente relacionado a um significado social [...] indicando que as mulheres negras, enquanto penteavam as filhas, reafirmavam a força da identidade e do engajamento, mas, realiza um salto mais alto que o estético na preservação da cultura que não foi escrita”.

* Doutorando em Educação pela Universidade Federal do Rio Grande do Sul, Porto Alegre, Rio Grande do Sul - Brasil.

** Professora Doutora do Programa de Pós-Graduação em Educação da Universidade Federal do Rio Grande do Sul, Porto Alegre, Rio Grande do Sul - Brasil.

**** Mestranda no Programa de Pós-Graduação em Educação da Universidade Federal do Rio Grande do Sul, Porto Alegre, Rio Grande do Sul - Brasil.

\section{Correspondência}

Ivan Livindo de Senna Corrêa - Universidade Federal do Rio Grande do Sul, Colégio de Aplicação. Av. Bento Gonçalves, 9500, Agronomia, CEP: 91501-970 - Porto Alegre, Rio Grande do Sul - Brasil.

E-mail: ivanlivindo@gmail.com - clarafis@cpovo.net-jusantosbr@hotmail.com

Recebido em 04 de março de 2013

Aprovado em 31 de julho de 2013 
